\title{
DRIVER ASSISTANCE SYSTEM FOR DISORDERED PEOPLE
}

\author{
Dr. Veena S \\ Professor, Department of computer science and engineering \\ Kanmani G, Manju V, Pavithra V \\ Student, Department of computer science and engineering
}

\begin{abstract}
Autonomous driving is currently a very active research area with virtually all automotive manufacturers competing to bring the first autonomous car to the market. This race leads to billions of dollars being invested in the development of novel sensors, processing platforms, and algorithms. In this paper, we explore the synergies between the challenges in self-driving technology and development of navigation aids for blind people and hearing loss people. The study of leverage the recently emerged methods for self-driving cars, and use it to develop assistive technology for the visually impaired, hearing impaired and mentally retarded. the task of perceiving the environment in real time from cameras. First, we review current developments in embedded platforms for real-time computation as well as current algorithms for image processing, obstacle segmentation and classification, machine learning, deep learning, iot. Our study shows that what are the problem facing visually impaired, hearing impaired and mental retarded people while driving.
\end{abstract}

\section{INTRODUCTION}

Humans rely strongly on vision, our primary sense used for perception of surroundings. Our everyday life independence is closely connected to the flexibility to explore new environments and detect obstacles in an exceedingly safe way. Navigation in an unknown setting is therefore awfully difficult task for visually impaired people, often limiting their independence. World Health Organization estimates around 285 million people worldwide to be visually impaired with around 39 millions being diagnosed with blindness [2]. Especially developed countries, the demand for assistive technologies for the blind grows because of the demographic shift towards an elderly population, the group most vulnerable to low vision. Still, the marketplace for vision-based navigation aids for the visually impaired remains small. In contrast, strong interest in autonomous vehicles accelerated the progress in new technologies, creating a awfully active research field. Problem statements during this area are often associated with computer vision, as understanding what's occurring outside and handling uncertain situations even under difficult climatic conditions is crucial for traffic safety. this can be very like the challenges visually impaired people face in their way of life. The booming field of autonomous driving can therefore also result in progress within the much smaller domain of Assistive technologies for the blind. Bringing those applications together and discussing, how development of recent aids for visually impaired people can have the benefit of much larger automotive industry, is that the main topic of this work. Our user study show that what are the matter facing visually impaired, hearing impaired and mental retarded people while driving.

\section{SURVEY ON EXISTING SYSTEM FOR DISORDERED PEOPLE WHILR DRIVING}

V. J. Verhoeven, K. T. Wong, G. H. Buitendijk and et al., "Visual Consequences of Refractive Errors in the General Population," [1] has proposed the prevalence of myopia which increased worldwide in recent decades and now could be endemic over the whole industrial world. This increase is especially caused by changes in lifestyle and behavior. specifically, the quantity of outside activities and near work would display a very important role within the pathogenesis of the disease.

Ayat A. Nada, Mahmoud A.Fakhr, and Ahmed F. Seddik "Assistive IEEE Technical sponsored science and information conference"[2] has proposed to enable them based on a camera connected to Raspberry Pi embedded board which captures the image on the object to detect cars and humans. This system sends feedback in the form of speech warning message via an earphone. The smart system is of fast, low cost and light weight. 


\section{International Journal of Engineering Applied Sciences and Technology, 2020 \\ Vol. 4, Issue 10, ISSN No. 2455-2143, Pages 242-246 \\ Published Online February 2020 in IJEAST (http://www.ijeast.com)}

J Z hang,RXiong,C Zhao, Y Zhang,S Ma,W Gao[3]has proposed an object detection approach using spatial histogram features. The spatial histogram consist of a marginal distributions of an image over local patches, they can preserve texture and shape information of an object simultaneously. This has two different kinds of objects: car and video text.

.Cheng,B.Jeng,P.Tseng and K.C.Fan.Lane detection with moving vehicles within the traffic scenes[4]has developed an assistive navigation system for the blind has propose a strong method for detecting the pedestrian marked lanes at traffic junctions. The proposed method includes two stages:regions of interest(ROI) extraction and lane marker verification. The ROI extraction is performed by using color and intensity formation. A probabilistic framework employing multiple geometric cues is then accustomed verify the extracted ROI.

P.Strumillo, [5 ]has proposed assistive technology solutions for pedestrians with the disability and divulges that almost all of the prevailing solutions address a selected a part of the travel problem. Technology-centered approach with limited target the user needs is one in every of the main concerns within the design of most of the systems. State-of-the-art sensor technology and processing techniques are getting used to capture details of the encompassing environment. the important challenge is in conveying this information in a very simplified and understandable form especially when the alternate senses of hearing, touch, and smell have much lesser perception bandwidth than that of vision.

M.S.Uddin and T. Shioyama, "Bipolarity and projective invariant-based zebra-crossing detection for the visually impaired," [6] has proposed the Cross watch System which uses computer vision to produce information about the placement and orientation of crosswalks to a blind or a visually impaired pedestrian holding a camera cellphone. Real-time performance on the telephone, whose computational resources are limited compared to the kind of desktop platform usually utilized in computer vision, is formed possible by coding in Symbian C++. Tests with blind subjects demonstrate the feasibility of the system.

Roni Ash,Dolev Ofri,Jonathan Brokman,Idan Friedman, Yair Moshe[7]has propose a technique that may help visually impaired people by detecting the pedestrian traffic lights and their state from video taken with mobile phone camera. The proposed technique consist of two main modules:an object detector that uses deep convolutional network and a decision module. It aims to operate on a mobile phone in a client server architecture.

Justin A.Zakis a,Hugh J.McDermitt c,1,Amdrew E,Vandalia a[8] The proposed method uses peak detection algorithm in addition to minimum mean square error to detect acoustic siren signals. This method is implemented in frequency domains helps in differentiating the emergency signals from other surrounding noises. The entire data is simulated in MATLAB. This system not helps in reducing the time period for an emergency vehicle but also decreases the quantity of accidents during any such hassle.

Sung-Won Park, Jose Trevino, "Automatic Detection of Emergency Vehicles for Hearing Impaired Driver'[9] has proposed a straightforward algorithm to detect an emergency vehicle's siren using the linear prediction is presented. By measuring the means and variances of the reflection coefficients in an exceedingly pre selected number of successive frames, automatic detection of emergency vehicle's siren is feasible. it's been shown that only two coefficients are enough for successful detection. because of the simplicity of the algorithm, it may be implemented easily on any Texas Instrument's TMS DSPs.

Nagadeepa N.Enhanced Bluetooth Technology to Assist the Highway Vehicle Drivers[10] Overall in excess of 160 million individuals are outwardly impaired with 37 million to be blind. The need to for assistive devices was and will be consistent. There is an extensive variety of route frameworks and instruments existing for outwardly impaired people. The proposed device is utilized for controlling people who are blind or incompletely located. The device is utilized to help blind individuals to move without any difficulty and certainty as a located people.

Piotr Kardys,Adam Dabrowski,Marcin Iwanowski,Dmain Huderek [11] has proposed a replacement Android application for blind and visually impaired people. This device fulfil the requirements of a visually impaired person and thus capable of identifying traffic light lights, people and vehicle movement while crossing roads, identify currency notes, recognize obstacles, numerals act as already dark security camera.

R De Charette,F Nashashibi[12] has proposed a true Time Visual Traffic Lights Recognition supported Spot Light Detection and Adaptive Traffic Lights Templates. The system architecture we propose also has the benefits of being extensible and having minimal infrastructural reliance, thus with wide 


\section{International Journal of Engineering Applied Sciences and Technology, 2020 \\ Vol. 4, Issue 10, ISSN No. 2455-2143, Pages 242-246 \\ Published Online February 2020 in IJEAST (http://www.ijeast.com)}

usability. we've got developed an outside navigation application with integrated support for crossover guidance.

Nieto, M., Laborda, J.A., Salgado, L[13] has proposed a Road environment modeling using robust perspective analysis and recursive Bayesian segmentation. Machine Vision and Application. An important stage in such system is lane prediction and on-road-self-positioning. The model consists of the amount of lanes and vehicle position in those lanes as parameters, hence allowing the employment of high-level semantic knowledge. Under this formulation, we employ a lane-width-based model and a maximum-likelihood estimator making the strategy to find out to slight viewing angle variation. the approach is tested on real-world videos and is found to be effective.

R.ckhorn,H J Reitboeck,M Arndtet al[14] has proposed the entropy sequence of the output image from the initial gray image by pulse coupled neural network $(\mathrm{PCN})$.It has been employed in the image classification and mean square error(MSE)between the feature vector of the input image and standard feature vector is employed to evaluate the input image belong to which sort of image groups.

Mahdi Safaa A., Muhsin Asaad H. and AlMosawi Ali I[15] has proposed using Ultrasonic Sensor for blind and deaf persons Combines Voice Alert and Vibration Properties. This system proposes a camera based assistive text reading to assist visually impaired person in reading the text labels and products packaging from hand-held objects in their daily lives. The proposed idea involves text extraction from scanned image using Interaction Optical Character Recognition (OCR) and converting the text to speech by e-Speak tool. Also ultrasonic sensor is employed to detect any obstacles on the thanks to help blind man. the entire system is applied by using Raspberry pi and portability is achieved by employing a battery backup. This technology helps immeasurable people within the world who experience a big loss of vision.

\section{TRADITIONAL DRIVING ISSUES FOR DISORDERED PEOPLE}

Humans rely strongly on vision, our primary sense used for perception of surroundings. Our daily life independence is closely connected to the ability to explore new environments and detect obstacles in a safe way. Navigation in an unknown setting is therefore a very difficult task for visually impaired people, often limiting their independence. Blindness is a more severe problem among the disabilities of human. It is difficult to lead a normal life for blind like a sighted person. Because they cannot feel their surroundings. So, most of the blind peoples require travel freely in an unknown environment. Researchers were invented to make independent navigation for blinds. But most of them are invented for a specific task or the devices do not cost friendly. To gain independent navigation, a device with more features is required.

\section{APPROACH TOWARDS AR IMPLEMENTATION OF DISORDERED PEOPLE WHILE DRIVING}

Tactile maps and diagrams are widely used as accessible graphical media for people with visual defect, particularly within the context of education. They can be made interactive by hearing them with audio feedback. It is however complicated to make audio tactile graphics that have rich and realistic tactile textures. To overcome these limitations, we propose a brand new approach allowing no voices to simply and quickly augment real objects with audio feedback (AR) has emerged as the simplest way to visualize information woven into the physical environment. In AR it's the dual- nature d, highlighting not only the unique attributes of AR, but emphasizing the robustness of traditional best practice values to which its implementation must adhere. 
International Journal of Engineering Applied Sciences and Technology, 2020

Vol. 4, Issue 10, ISSN No. 2455-2143, Pages 242-246

Published Online February 2020 in IJEAST (http://www.ijeast.com)

V. COMPARISON OF EXISTING WORKS

\begin{tabular}{|c|c|c|c|c|}
\hline S.NO & TITLE & TECHNOLOGY & ADVANTAGES & DISADVANTAGES \\
\hline 1 & $\begin{array}{l}\text { Face detection and road sign } \\
\text { detection for blind people }\end{array}$ & Raspberry Pi & $\begin{array}{l}\text { Accomplishing right } \\
\text { recognition exactness } \\
\text { on people and autos } \\
\text { location for ongoing } \\
\text { testing with daze }\end{array}$ & $\begin{array}{l}\text { Identifying snags amid } \\
\text { strolling in the road } \\
\text { which makes it } \\
\text { hazardous }\end{array}$ \\
\hline 2 & $\begin{array}{l}\text { Infrared sensor based } \\
\text { detection for blind people }\end{array}$ & Smart stick & $\begin{array}{l}\text { Detects an objects and } \\
\text { sends a feedback in } \\
\text { the form of speech } \\
\text { warning message }\end{array}$ & $\begin{array}{l}\text { To correct the detection } \\
\text { accuracy on humans } \\
\text { and car detection for } \\
\text { real time testing with } \\
\text { blind people }\end{array}$ \\
\hline 3 & $\begin{array}{l}\text { Navigate blind and visually } \\
\text { impaired people }\end{array}$ & Autonomous car & $\begin{array}{l}\text { Build an obstacle } \\
\text { avoidance system for } \\
\text { blind and visually } \\
\text { impaired people that } \\
\text { is based on hardware } \\
\text { platform used in the } \\
\text { automotive industry }\end{array}$ & $\begin{array}{l}\text { Challenges and } \\
\text { modifications required } \\
\text { for such an application } \\
\text { domain transfer }\end{array}$ \\
\hline 4 & $\begin{array}{l}\text { Pedestrian Lane detection for } \\
\text { assistive navigation of blind } \\
\text { people }\end{array}$ & Pattern Recognition & $\begin{array}{l}\text { Build an illumination } \\
\text { conditions and obtains } \\
\text { superior performance } \\
\text { by extracting the } \\
\text { (ROI) Regions Of } \\
\text { Interest }\end{array}$ & $\begin{array}{l}\text { Detection can be } \\
\text { misplaced at any time }\end{array}$ \\
\hline 5 & $\begin{array}{l}\text { Driver assistive solutions for } \\
\text { visually impaired people }\end{array}$ & $\begin{array}{l}\text { Image based sense of hearing } \\
\text { recognition techniques }\end{array}$ & $\begin{array}{l}\text { Mobility of blind } \\
\text { person involves } \\
\text { perception of } \\
\text { obstacles,lanemarks } \\
\text { and orientation }\end{array}$ & $\begin{array}{l}\text { Need to Improve the } \\
\text { accuracy of blind } \\
\text { people while driving }\end{array}$ \\
\hline 6 & $\begin{array}{l}\text { Transfer of driver assistance } \\
\text { algorithms for blind and } \\
\text { visually impaired people }\end{array}$ & Machine Learning & $\begin{array}{l}\text { Smart phone based } \\
\text { driver assistance for } \\
\text { the blind and visually } \\
\text { impaired people by } \\
\text { detecting algorithms } \\
\text { in the traffic domain }\end{array}$ & $\begin{array}{l}\text { Adaptation of a cross } \\
\text { walk detection }\end{array}$ \\
\hline 7 & $\begin{array}{l}\text { Object detection and driver } \\
\text { assistance of disordered } \\
\text { people }\end{array}$ & $\begin{array}{l}\text { Object Detector that uses } \\
\text { deep } \\
\text { Network(CNN) Convolutional } \\
\text { decision techniques }\end{array}$ & $\begin{array}{lr}\text { Helps the visually } \\
\text { impaired people by } \\
\text { detecting } \\
\text { pedestrian } \\
\text { lights }\end{array}$ & $\begin{array}{l}\text { Improve the accuracy } \\
\text { of driver assistance }\end{array}$ \\
\hline
\end{tabular}


International Journal of Engineering Applied Sciences and Technology, 2020

Vol. 4, Issue 10, ISSN No. 2455-2143, Pages 242-246

Published Online February 2020 in IJEAST (http://www.ijeast.com)

\begin{tabular}{|c|c|c|c|c|}
\hline 8 & $\begin{array}{l}\text { Siren detection and driver } \\
\text { assistance of disordered } \\
\text { people }\end{array}$ & $\begin{array}{l}\text { Modified min mean squared } \\
\text { error method }\end{array}$ & $\begin{array}{l}\text { Reducing the travel } \\
\text { time for emergency } \\
\text { vehicle and also used } \\
\text { for disordered people }\end{array}$ & $\begin{array}{l}\text { Need to Improve the } \\
\text { accuracy for drivers by } \\
\text { detection }\end{array}$ \\
\hline 9 & $\begin{array}{llr}\text { Automatic detection } & \text { of } \\
\text { emergency } & \text { vehicles } & \text { for } \\
\text { hearing impaired drivers } & \end{array}$ & Linear Prediction technique & $\begin{array}{l}\text { Automatic detection } \\
\text { of emergency vehicles } \\
\text { in a pre selected } \\
\text { number of successive } \\
\text { frames }\end{array}$ & 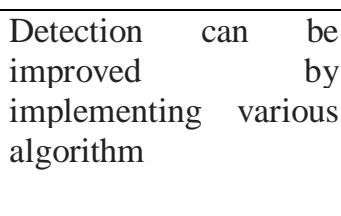 \\
\hline 10 & Navigate blind people & $\begin{array}{l}\text { Ultrasonic sensor and voice } \\
\text { alert, Vibration properties }\end{array}$ & $\begin{array}{l}\text { Benefit the blind and } \\
\text { voice alert feature }\end{array}$ & $\begin{array}{l}\text { Improve the assist for } \\
\text { blind people }\end{array}$ \\
\hline 11 & $\begin{array}{l}\text { Recognize detection of } \\
\text { visually impaired people } \\
\text { using traffic sign lights }\end{array}$ & Android Application tools & $\begin{array}{l}\text { Fulfills the needs of } \\
\text { visually impaired } \\
\text { people while crossing } \\
\text { the road }\end{array}$ & $\begin{array}{lr}\text { Improve } & \text { the } \\
\text { recognition } & \text { and } \\
\text { communication } & \end{array}$ \\
\hline 12 & $\begin{array}{l}\text { Real Time Visual Traffic } \\
\text { Light Recognition }\end{array}$ & $\begin{array}{l}\text { Spot light detection and } \\
\text { adaptive traffic light templates }\end{array}$ & $\begin{array}{l}\text { Have an minimal } \\
\text { infrastructural } \\
\text { reliance, thus allowing } \\
\text { a wider usability }\end{array}$ & $\begin{array}{l}\text { Challenging the real } \\
\text { time traffic for visually } \\
\text { impaired people }\end{array}$ \\
\hline 13 & $\begin{array}{l}\text { Road environment modelling } \\
\text { using perspective analysis }\end{array}$ & $\begin{array}{lll}\text { Machine } & \text { Vision } & \text { and } \\
\text { Application } & & \end{array}$ & $\begin{array}{l}\text { Lane prediction and } \\
\text { on-road-self } \\
\text { positioning consists of } \\
\text { number of lanes and } \\
\text { vehicle positions }\end{array}$ & $\begin{array}{l}\text { Improve the analysis } \\
\text { feedback }\end{array}$ \\
\hline 14 & $\begin{array}{l}\text { Oscillatory and non } \\
\text { oscillatory synchronization in } \\
\text { the visual cortex }\end{array}$ & $\begin{array}{l}\text { Pulse coupled } \\
\text { Network(PCN)used in image } \\
\text { classification and mean square } \\
\text { error }\end{array}$ & $\begin{array}{l}\text { Classifies the image } \\
\text { by using the visual } \\
\text { features and check that } \\
\text { image belongs to the } \\
\text { original image }\end{array}$ & $\begin{array}{l}\text { Detection can be used } \\
\text { in a wrong inattention } \\
\text { for a blind people }\end{array}$ \\
\hline 15 & $\begin{array}{l}\text { Wireless Alert system for } \\
\text { visually impaired people }\end{array}$ & $\begin{array}{cc}\text { Optical } & \text { Character } \\
\text { Recognition(OCR) } & \end{array}$ & $\begin{array}{lr}\text { Camera } & \text { based } \\
\text { assistive text reading } \\
\text { to help visually } \\
\text { impaired person in } \\
\text { reading text labels }\end{array}$ & \\
\hline
\end{tabular}

\section{CONCLUSION}

By using the above techniques that helps assistive technology for blind and hearing impaired people. To get assisted by the people that provides transferring information, data various medium.

\section{REFERENCES}

[1]V. J. Verhoeven, K. T. Wong, G. H. Buitendijk and etal., "Visual Consequences of Refractive Errors in the General Population,"

Ophthalmology, pp. 101-109, 2014.

[2]Ayat A. Nada, Mahmoud A. Fakhr, and Ahmed F. Seddik "Assistive IEEE Technically Sponsored Science and data Conference London,UK,2015. 
[3]J Z hang,RXiong,C Zhao,Y Zhang,S Ma,W Gao IEEE Transactions on Image Processing 2(3),12461259,2016.

[4] H.Cheng,B.Jeng,P.Ts eng,and K.C.Fan.Lane detection with moving vehicles within the traffic scenes.IEEE Trans.on Intelligent Transportation Systems, 7(4):571-582,2006.

[5] P. Strumillo, "Electronic interfaces aiding the visually impaired in environmental access, mobility and navigation," in Conference on Human System Interactions, 2010, pp. 17-24. 1

[6] M. S. Uddin and T. Shioyama, "Bipolarity and projective invariant-based zebra-crossing detection for the visually impaired," in IEEE Conference on Computer Vision and Pattern Recognition, 2005, pp. 22-30. 1

[7] Roni Ash ; Dolev Ofri ; Jonathan Brokman ; Idan Friedman ; Yair Moshe "International Conference on science and electrical engineering",cilat,Israel-2013

[8] Justin A.Zakis a,Hugh J.McDermitt c, 1,Amdrew E,Vandalia a,"A first harmonic estimator for the data processing of musical sounds for cochler implants",Speech Communication49(2007)113-122.

[9]Sung-Won Park, Jose Trevino, "Automatic Detection of Emergency Vehicles for Hearing

Impaired Driver", Texas A\&M University-Kingsville EE/CS Department MSC 192 Kingsville J. Acoust. Soc. Am., vol. 50, pp. 637-665, 2013.

[10]Nagadeepa N,Enhanced Bluetooth Technology to help the Highway Vehicle Drivers.Res.J.Recent Sci.1(8),82-85(2012).

[11]Piotr Kardys,Adam Dabrowski,Marcin Iwanowski,Dmain Huderek $2016 \quad$ Signal Processing:Algorithms,Architectures,Arrangements and Applications(SPA).

[12]R De Charette,F Nashashibi. Real time visual traffic lights recognition supported spot light detection and adaptive traffic lights templates. 2009 IEEE Intelligent Vehicles Symposium

[13]M Nieto,J A Laborda,L Salgodo Machine Vision and Applications22(6),927-945,2011.

[14]R.Eckhorn,H.J.Reitboeck,M.Arndt et al.,'Feature Linking via Synchronization among Distributed Assemblies:Simulations of Results from cat cortical area,'Neural Computation,2(3),293-307(1990).

[15] Mahdi Safaa A., Muhsin Asaad H. and AlMosawi Ali I, "Using Ultrasonic Sensor for Blind and Deaf persons Combines Voice Alert and Vibration Properties", Research Journal of Recent Sciences ISSN 2277-2502 Vol. 1(11), 50-52, November (2012). 